\title{
An analysis of inequality of economic opportunity in Thailand
}

\author{
Montchai Pinitjitsamut a* \\ a Department of Agricultural and Resource Economics, Faculty of Economics, Kasetsart University, Thailand. \\ ${ }^{*}$ Corresponding author's e-mail: montchai.p@ku.ac.th
}

\author{
H I G H L I G H T S: \\ 1. This study focus on understanding the economic opportunities of labor force in Thailand \\ 2. Age and material status positively explains the economic opportunities measured in term of labor income. \\ 3. Fortunately, result reveals that the inequality parameter in Thailand is not as too high.
}

\begin{tabular}{ll}
\hline Article History & ABSTRACT \\
\hline $\begin{array}{l}\text { Received: 23-10-2014 } \\
\text { Revised received: 07-11-2014 }\end{array}$ & $\begin{array}{l}\text { This study aims to understand the socioeconomic and family backgrounds that affect } \\
\text { individual economic opportunity in term of labor income on and above average income in } \\
\text { Accepted: 06-12-2014 }\end{array}$ \\
$\begin{array}{l}\text { different regions of Thailand. The results present that both age and marital status have } \\
\text { positive impact to individual's economic opportunity. Because it related to the necessity in } \\
\text { personal family life. People works in Bangkok not necessary to get economic opportunity } \\
\text { greater than others. Most inequality indicators show the inequality situation in Thailand still }\end{array}$ \\
$\begin{array}{l}\text { Keywords: } \\
\text { not as high as expectation. However, ordinary person usually get only less than 50\% } \\
\text { opportunity; }\end{array}$ & $\begin{array}{l}\text { (0.4855) opportunity to get earning equal or more the average. Also, the society should } \\
\text { concern the inequality of economic opportunity in optimal level which make equality } \\
\text { parameter not greater than 0.5. This will create the mechanism to minimize the level of } \\
\text { Inequality measure; }\end{array}$ \\
inequality, as a whole.
\end{tabular}

JEL Classification:

I31; I30; I39.

DOI: http://dx.doi.org/10.18533/jefs.v2i04.74

(c) 2014 The Authors. This is an open access article under the terms of the Creative Commons Attribution License 4.0, which allows use, distribution and reproduction in any medium, provided the original work is properly cited.

\subsection{Introduction}

In Thailand, an inequality of economic opportunity still undiscovered issue. The study mainly focuses on the distribution of income and income inequality. However, the income inequality improved over a decade. Gini coefficient increased significantly from 0.42 in 2004 to 0.47 in 2007 and 0.47 in 2009. Hence, the economic opportunities of individuals are influenced by socio-economic factors, such as income, innate ability, educational ability, as well. Socio-economic factors mostly inter-influence each other's. For instance, personal economic opportunity, influencing by education achievement, impacts to personal future income and would be create the next generation economic opportunity.

For all definitions, there is a notion of inborn abilities or fitness of individuals which are relevant to earning power. They may relate to intellectual capacities, to physical skills, to personality, or to other aspects. They may influence earnings directly via facilitating schooling and training. These relationships are shown as Figure 1, supplemented by a chance or stochastic factor at each stage (Atkinson, 1983). If the earnings relationship holds in identical form for everyone with the same distribution of chance variable, then the conditions for earning is the same for all people with identical innate abilities. When do they generate inequality of opportunity? First, the earnings relationship may not be the same for everyone. There may, for example, be systematically higher earnings for people of one race or sex to 
religious group, and this may persist even in a perfectly competitive economy. This is referred to here as 'discrimination', although it may encompass a variety of phenomena, including possibly some factors which might otherwise have been related as part of the stochastic term. Second, there may be a systematic link with family background: the privileges enjoyed by the children of higher income parents (Atkinson, 1983).

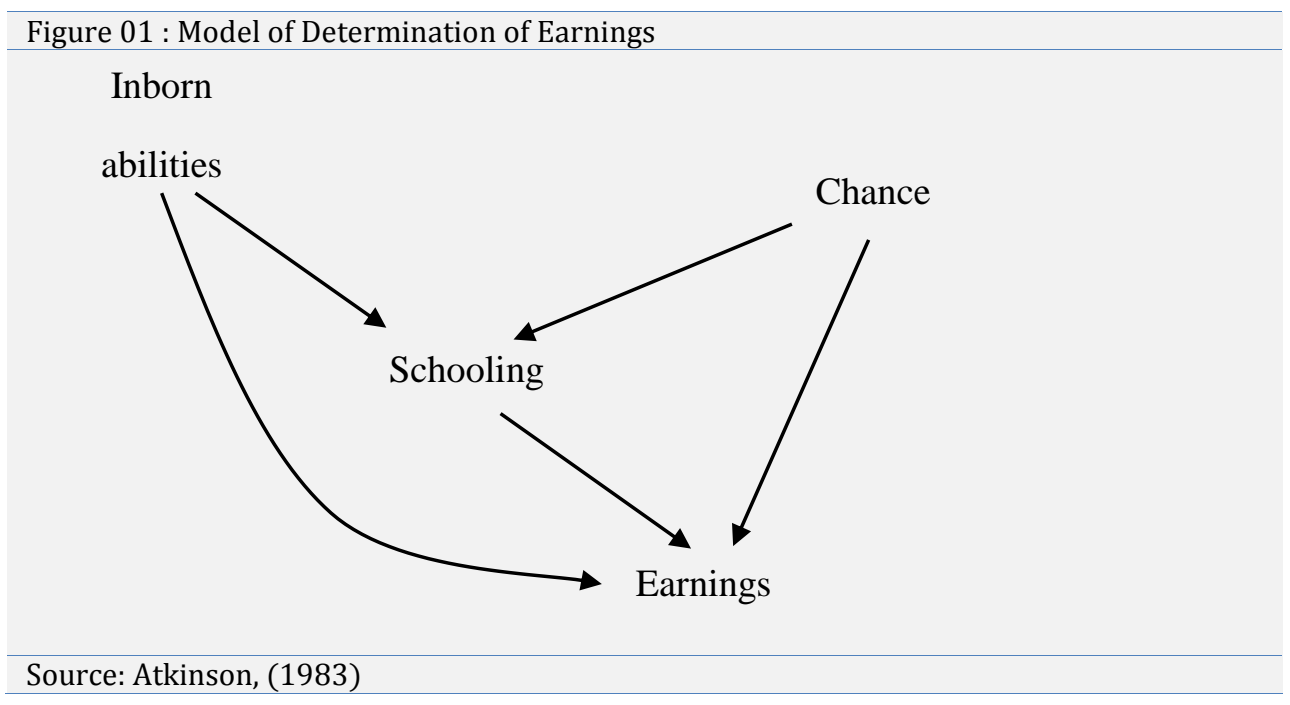

The equality of opportunity is usually presented in the notion of fairness (Rawls, 1973) which conceptually means the right of different groups of people to have a similar social position and receive the same treatment or everyone is treated fairly and equally. There is the equality in the assignment of basic rights and duties given that social and economic are inequalities (Rawls, 1973). Similarly, the equality of opportunity is expressed as "level the playing field" among individuals who compete for positions be admission to pools of candidates competing for positions and "nondiscrimination" principle states that the decision are judged only with respect to those relevant attributes and not with other such as race, gender, social and income status, place of residence (Roemer, 1998).

Then, the level of playing field states that the society should encourage equality among individuals who compete for positions. However, this principle accepts the variety of personal natural abilities so that, all those with relevant potentials or abilities will be admissible to candidate pool competing for positions. The other, nondiscrimination principle, states that those individual's possible occupancy of the position be judged only with respect to those relevant attributes regardless of race, religion, gender, social status, income status and education level, (Roemer, 1998).

Indeed, the conception of equality of opportunity is till elusive and complex in practice. The genuine equality of opportunity may be difficult to observe but the inequality of opportunity can be simply identified. Okun (1980) expresses the inequality of opportunity which does arises may cause concerns for two reasons. First, even if individuals start equally placed, there may be differences of outcomes which is called 'casino'. Second, individuals have differing initial advantages, arising from natural abilities, family background, or other factors.

\subsection{Material and methods}

This study was conducted using Socio-economic survey data set from 2009 and the findings on Mincer equation on Age-Earning Profile from Pinitjitsamut (2012), shown as follow.

$\log E=a_{0}+a_{1} E X P+a_{2} E X P^{2}+a_{3} M R Y+a_{4} B K K+a_{5} P R V$

Where, EXP stands for years of experience with the assumption of starting work immediately or in the next year following graduation. MRY represents marital status variable that is equal to 1 , if married and $=0$ otherwise. BKK and PRV stands for living area (live in Bangkok, $\mathrm{BKK}=1$ and $=0$, otherwise) and type of working organization (work for private company, $\mathrm{PRV}=1$ and $=0$, otherwise). The result of estimation on Age-Earning profile is shown as follow.

\begin{tabular}{|c|c|c|c|c|c|c|c|c|}
\hline \multirow{2}{*}{ Level } & \multicolumn{6}{|c|}{ Variables } & \multirow{2}{*}{ Adj. $R^{2}$} & \multirow{2}{*}{ F-statistic } \\
\hline & Constant & EXP & EXP2 $^{2}$ & MRY & BKK & PRV & & \\
\hline \multirow[b]{2}{*}{ High school } & 8.3501 & 0.0288 & -0.0002 & 0.1397 & 0.404 & 0.055 & \multirow[b]{2}{*}{0.167} & \multirow[b]{2}{*}{$201.21^{c}$} \\
\hline & $(0.034)^{c}$ & $(0.002)^{c}$ & $(0.000)^{c}$ & $(0.023)^{c}$ & $(0.028)^{c}$ & $(0.021)^{c}$ & & \\
\hline
\end{tabular}




\begin{tabular}{|c|c|c|c|c|c|c|c|c|}
\hline \multirow{2}{*}{ University } & 8.8766 & 0.0637 & -0.0006 & 0.1068 & 0.285 & 0.027 & \multirow{2}{*}{0.383} & \multirow{2}{*}{841.39} \\
\hline & $(0.033)$ & $(0.002)^{c}$ & $(0.000)^{c}$ & $(0.014)$ & $(0.021)^{c}$ & $(0.014)^{a}$ & & \\
\hline
\end{tabular}

Note: Superscript of a, b, c are stand for $1 \%, 5 \%, 10 \%$ statically significant, respectively.

\subsection{Individual's opportunity estimation}

By using $\pi_{i}$ parameter, the relationship between economics opportunity and socioeconomic factors be described as follows.

$$
\begin{array}{ll}
\pi_{i t}^{*}=\beta_{t}^{\prime} X_{i t}+\varepsilon_{i t} & , \varepsilon_{i t} \sim N(0,1) \\
\pi_{i t}=1 \text { if } \pi_{i t}^{*}>0 & \text { and } \pi_{i t}=0 \text { if } \pi_{i t}^{*} \leq 0
\end{array}
$$

Where $\pi_{i t}^{*}$ is an unobserved variable which is implied to individuals' tastes and ability reflecting their economic opportunity at particular time, $t$ and $\pi_{i t}$ the actual of that process. The $X_{i t}$ are a set of explanatory variables and

$\beta_{t}^{\prime}$ is a parameter vector. Both are in the pattern of normal cumulative distribution function.

$$
\operatorname{Pr}\left(\pi_{i}=1\right)=E\left(\pi_{i}=1 \mid S E S_{j i}\right)=F\left(S E S_{j i}\right)=\beta_{j} S E S_{j i}
$$

Where $F($.$) is the cumulative distribution function of normal distribution, and S E S_{j i}$ is the vector of socioeconomics factors such as gender, social status, household head occupation, etc.

$$
\operatorname{Pr}\left(\pi_{i}=1\right)=\beta_{1}+\beta_{2} \cdot S C H+\beta_{3} \cdot A G E+\beta_{4} \cdot M R Y+\beta_{5} \cdot B K K+\beta_{6} \cdot P R V
$$

Where, $\operatorname{Pr}($.$) represents individual's probability to get income equal or greater than average level (\operatorname{Pr}()=$.1 , otherwise $=0$ ). SCH is years of schooling, AGE represents years of working experience, MRY is dummy variable stand for marital status (married $=1$, otherwise $=0$ ), $\mathrm{BKK}$ is dummy variable represents residence area (live in Bangkok=1, otherwise $=0$ ) and, also, PRV is dummy variable represents working organization (Private company $=1$, otherwise $=0$ ).

In this case threshold is set to zero, but the choice of threshold value is irrelevant due to a constant term is include in. Therefore, the marginal effect of Probit equation can be expressed as follow.

$$
\frac{\partial E[y \mid x]}{\partial x}=\phi\left(x^{\prime} \beta\right) \beta
$$

Then, the marginal effect for dummy variable can be calculated from the following equation.

$$
\frac{\partial E[y \mid x]}{\partial x}(\text { Dummy })=\operatorname{Pr}\left[Y=1 \mid \bar{x}_{(d)}, d=1\right]-\operatorname{Pr}\left[Y=1 \mid \bar{x}_{(d)}, d=0\right]
$$

MRY, BKK and PRV are dummy variables reflecting individual economic opportunity and having wide various aspects. It refers to the highly dispersion of individual economic opportunity.

\subsection{Measure of equality of opportunity}

An equality of opportunity is measured by using the probability value in terms of frequency distribution. The probability value is demonstrated on means, median or mode and categorized as a group of quartile, quintile, deciles or percentiles. The analysis can be done by comparing among the selected groups e.g. top quintile and bottom quintile. Addition, Measures of dispersion can also be used to analyze frequency distributions; standard deviation, coefficient of variation, and measures of skewness.

However, the most commonly used measure on the detailed analyzing of the distribution of education opportunities are representation index, the Lorenz curve, and the Gini coefficient, which usually are compared with a perfectly 
equal distribution. Lorenz curve, which is expressed the distribution of opportunity among people or households, can give a good visual picture of the degree of equality. Two or more of curves are drawn on the same diagram may use to compare distributions. The Gini coefficient is a measure of the degree of equality of opportunity and can be expressed as.

$$
G=\frac{1}{2 n^{2} \bar{p}} \sum_{i=1}^{n} \sum_{j=1}^{n}\left|p^{i}-p^{j}\right|
$$

Where $p^{i}$ and $p^{j}$ is the probability of $i^{\text {th }}$ and $j^{\text {th }}$ household

The Gini coefficient is based on the Lorenz curve and also calculated diagrammatically by the ratio of the $45^{\circ}$ line curve area and triangle area of the $45^{\circ}$ line. If opportunities are distributed completely equally, it will be zero; and if one person has all the opportunities, it will be unity.

The Atkinson index is another measure which considers distributional values explicitly. It is based on a social-welfare function and with constant relative inequality aversion, $\varepsilon$, as an explicit representation of distributional values. The Atkinson measure is given by

$$
A=1-\left[\sum_{i=1}^{N}\left(\frac{p^{i}}{\bar{p}}\right)^{1-\varepsilon} f\left(p^{i}\right)\right]^{1 /(1-\varepsilon)} \quad \varepsilon \neq 1
$$

Where $p^{i}$ is the probability of $i^{\text {th }}$ household, $f\left(p^{i}\right)$ is the proportion of the population with probability in the $i^{\text {th }}$ range, $\bar{p}$ is mean of probability. The value of index ranges 0 to $1(0 \leq A \leq 1)$. The index equal to zero, $A=0$, if the $p^{i}=\bar{p}$ for all households $i$, which the probabilities are distributed equally, or $\varepsilon=0$. The value of $\varepsilon$ causes by the deviation of $p^{i}$ from $\bar{p}$. The greater the deviation $p^{i}$ from $\bar{p}$ and the higher the value of $\varepsilon$, the greater the value of $A$. If $\varepsilon=0$, society is indifferent to inequality, and $A$ is zero. If $\varepsilon=\infty$, society is concerned only with the position of the lowest individual or income group.

\subsection{Empirical finding}

Estimation results can be shown as follow. Estimated probability represents an individual economic opportunity and be influenced from personal socio-economic characters. The results show that all socio-economic factors have directly impact to personal probability at $1 \%$ and $10 \%$ statistical significant.

$$
\begin{aligned}
\operatorname{Pr}\left(\pi_{i}=1\right)= & -88.93+1.16 \cdot S C H+2.06 \cdot A G E+0.60 \cdot M R Y-0.21 \cdot B K K-8.56 \cdot P R V \\
& (2.80)^{* * *} \quad(0.04)^{* * *} \quad(0.06)^{* *}(0.08)^{* * *} \quad(0.12)^{*}(0.28)^{* * *}
\end{aligned}
$$

Table 2. Coefficients of estimated Probit equation

\begin{tabular}{lccc}
\hline \multicolumn{1}{c}{ Independent variables } & Coefficient & z-statistics & Marginal effect \\
\hline Constant & -88.93 & $(-31.7431)^{* * *}$ & 0.1486 \\
SCH & 1.16 & $(31.2198)^{* * *}$ & 0.7221 \\
AGE & 2.06 & $(31.7735)^{* * *}$ & 0.5998 \\
MRY & 0.60 & $(7.3708)^{* * *}$ & -0.2066 \\
BKK & -0.21 & $(-1.7505)^{*}$ & 0.0001 \\
PRV & -8.56 & $(-30.7266)^{* * *}$ & \\
\hline
\end{tabular}

Note: z-statistics are in parentheses. ${ }^{* * *}$ denotes statistical significance at the $1 \%$ level; ${ }^{*}$ denotes statistical significance at the $10 \%$ level.

Marginal effects of all variables are shown in Table 2. Age and marital status are the most influencing factors to individual's economic opportunity. This reflects the actual family life of Thai people. Moreover, individuals' income directly relate to their experiences and family necessity. Then, years of schooling is another positive factor to economic opportunity with 0.1486 increasing for one year addition. People works in Bangkok not necessary to get economic opportunity greater than others. The factor has small negative relationship to personal opportunity. It can 
be explained through cost of living and high average income of personal living in Bangkok. Lastly, the working organization factor has no impact to individual economic opportunity.

\section{0} Inequality of economic opportunity in Thailand

Lorenz curves clearly presents the inequality level in economic opportunity among people in Thailand. Individuals from high income family normally gain more economic opportunity than whom from low income family. Categorizing in quintile, individual from Q4 and Q5 get economic opportunity $30 \%$ and $40 \%$ in proportion greater than the one from Q1. While the first three groups (Q1, Q2 and Q3), containing 60\% of population, get overall economic opportunity only $30 \%$ in proportion.

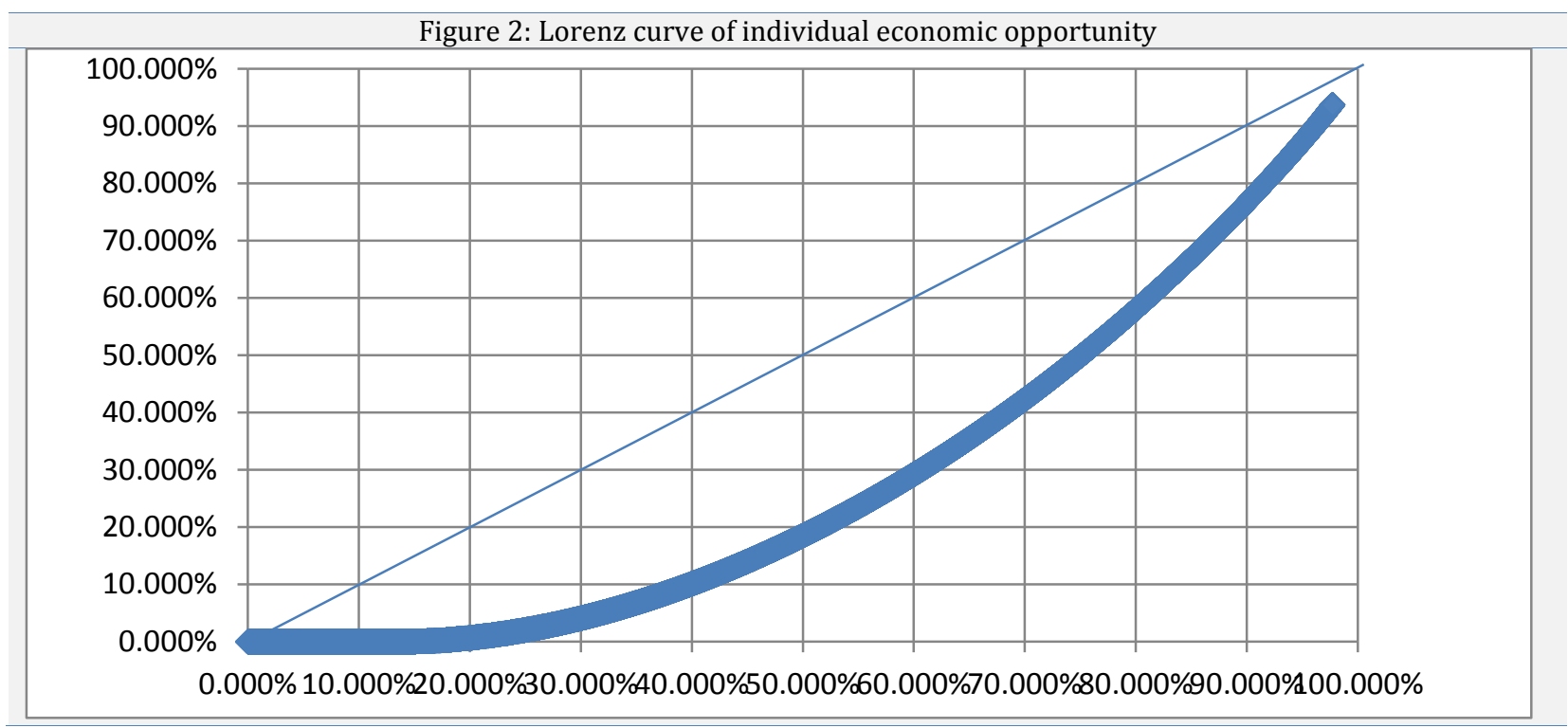

Source: Author's calculation

In country perspective, an inequality of economic opportunity can be illustrates through Gini coefficient which equal to 0.2129 . The coefficient is vary from 0.00 (Absolute Equality) to 1.00 (Absolute Inequality). It means that the inequality on economic opportunity situation in Thailand is not severe as much as our expectation. Furthermore, Atkinson index is another indicator expressing more details on inequality situation. By varying the inequality parameter, $\varepsilon$, the result presents that the optimal level of inequality parameter $\varepsilon$ should not greater than 0.5 . The more inequality parameter value, the more society concerns on inequality policy on favor of disadvantage groups (Chapman, Bruce and Ryan, Chris, 2005). Atkinson index presents the level of inequality of economic opportunity the same as Gini coefficient, particularly when $\varepsilon=0.5$. Variance and Coefficient of Variation both are another indicators presenting inequality among specific members. Variance and coefficient of Variation are 0.8217 and 1.8670 , respectively. It shows some specific low level of inequality of economic opportunity in Thailand. However, the average individual probability in economic is 0.4855 which can represents a general level of economic opportunity for individual in Thailand.

\begin{tabular}{lc}
\hline \multicolumn{2}{c}{ Table 3. Inequality of Economic Opportunity in Thailand 2009 } \\
\hline Indicator & Value \\
\hline Mean & 0.4855 \\
Gini coefficient & 0.2129 \\
\hline \multicolumn{1}{c}{0.1} & 0.0352 \\
0.5 & 0.2279 \\
1.0 & 1.1002 \\
2.0 & 1.0000 \\
5.0 & 0.9946 \\
Variance & 0.8217 \\
Coefficient of Variation & 1.8670 \\
\hline \multicolumn{2}{c}{ Source $:$ calculate by author } \\
\hline
\end{tabular}




\subsection{Conclusion}

The findings present that both age and marital status have positive impact to individual's economic opportunity. Because it related to the necessity in personal family life. People works in Bangkok not necessary to get economic opportunity greater than others. Most inequality indicators show the inequality situation in Thailand still not as high as expectation. However, ordinary person usually get only less than $50 \%(0.4855)$ opportunity to get earning equal or more the average. Also, the society should concern the inequality of economic opportunity in optimal level which makes equality parameter not greater than 0.5 . This will create the mechanism to minimize the level of inequality, as a whole. Public policies encouraging the equality of opportunity in Thai's society should be concerned these influence factors and, high priority, favor to the family with less economic opportunity.

\section{Acknowledgement}

This research project was funded by the Thailand Research Fund in 2012. The author would like to thank the referees and the editor for their useful comments and also thank the Thailand Research Fund - Academic section for funding support to this research project.

\section{References}

Atkinson, A.B., 1983. Social justice and public policy. Cambridge, Mass.: The MIT Press.

Becker, G.S., 1993. Human capital: A theoretical and empirical analysis with special reference to education. 3rded., Chicago: The University of Chicago Press. http://dx.doi.org/10.7208/chicago/9780226041223.001.0001

Chapman, B. and Ryan, C., 2005. The access implications of income-contingent charges for higher education: lessons from Australia. Economics of Education Review, 24: 491-512. http://dx.doi.org/10.1016/j.econedurev.2004.08.009

Jacob, M., 1974. Schooling, experience and earnings. New York: Columbia University Press.

Okun, A.M., 1980. Equality of income and opportunity. In Wealth, Income, and Inequality. 2nd ed., Anthony Barnes Atkinson, ed., England: Oxford University Press, pp.15-23.

Pinitjitsamut, M., 2012. An estimation of lifetime earnings and return on undergraduate education investment for different fields: a case of Thailand. International Journal of Education Economics and Development, 3(2):149163. http://dx.doi.org/10.1504/IJEED.2012.047101

Rawls, J., 1973. A theory of justice. Cambridge, Mass.: Harvard University Press.

Roemer, J.E., 1998. Equality of opportunity, Cambridge, Mass.: Harvard University Press. 